\title{
Factors associated with loss to follow-up after occupational HIV exposure in Cape Town, South Africa: a retrospective cohort study
}

\author{
Nectarios Sophocles Papavarnavas ${ }^{1}$, Kathryn Manning ${ }^{1}$, Fahd Conrad ${ }^{2}$, Milah Govender ${ }^{3}$ and Gary Maartens ${ }^{4^{*}}$
}

\begin{abstract}
Background: There is limited data on factors associated with loss to follow-up (LTFU) of health care workers (HCWs) following occupational exposure to HIV, and most studies were conducted in an era when poorly tolerated antiretrovirals like zidovudine were used.

Methods: A retrospective cohort study was conducted of HCWs attending a referral hospital's Occupational Health Clinic in Cape Town, South Africa for post-exposure prophylaxis (PEP) during a period when tenofovir was available. Our primary outcome was LTFU at the 3-month visit. We selected seven variables a priori for our logistic regression model and ensured there were at least 10 outcome events per variable to minimize bias.

Results: Two hundred and ninety-three folders were evaluated for descriptive analysis. LTFU worsened with successive visits: $36 \%$ at 6 weeks, $60 \%$ at 3 months, and $72 \%$ at 6 months. In multivariate analysis at the 3 -month visit LTFU was associated with age (adjusted odds ratio (aOR), 0.6 per 10-year increase [95\% Cl, 0.5-0.9]), HCW category of doctor (aOR 2.7 [95\% Cl, 1.3-5.5]), and time from exposure to receiving PEP of more than $24 \mathrm{~h}$ (aOR 5.9 [95\% Cl, 1.3-26.9]).

Conclusion: We identified factors associated with LTFU of HCWs after occupational HIV exposure, which could be used to target interventions to improve follow-up.
\end{abstract}

Keywords: Loss to follow-up, Post exposure prophylaxis, Health care workers, HIV

\section{Background}

The World Health Organization (WHO) estimates 3 million occupational human immunodeficiency virus (HIV) percutaneous exposures occur among 35 million healthcare workers (HCWs) annually, with $90 \%$ of exposures occurring in resource limited settings [1]. HCWs exposed to potentially infectious material from a source patient with HIV infection, or unknown HIV status, are offered post-exposure prophylaxis (PEP) if this is appropriate, and attend several follow-up visits for PEP toxicity monitoring and exclusion of HIV infection. Although HIV seroconversion following occupational exposure is uncommon, early diagnosis is critical as treatment of early HIV infection reduces the risk of HIV transmission

\footnotetext{
*Correspondence: gary.maartens@uct.ac.za

${ }^{4}$ Division of Clinical Pharmacology, Department of Medicine, Groote Schuur Hospital, University of Cape Town, Cape Town 7925, South Africa Full list of author information is available at the end of the article
}

and has direct benefits for the individual by reducing morbidity and mortality $[2,3]$.

Attendance of HCWs to follow-up visits after occupational exposure to HIV has been highly variable, ranging from 0 to $98.9 \%$ in observational studies [4-13]. A literature search yielded three studies that evaluated factors associated with attendance to follow-up $[6,12,13]$. Two studies found that the type of HCW category did not influence attendance to follow-up, $[12,13]$ but one study found that HCW category did influence attendance to follow-up [6]. One study identified being exposed to an HIV seropositive source increased attendance to follow-up, [13] but another found this had no effect [6]. One study [13] reported that type of exposure and time to reporting did not influence attendance to follow-up; and women had better attendance to follow-up than men [13]. Sample size calculations were not reported in any of these three studies. Furthermore, many of the PEP 
regimens used in these studies included poorly tolerated antiretroviral drugs. A recent systematic review reported that tenofovir disoproxil fumarate (TDF) based PEP was better tolerated with higher completion rates than zidovudine based PEP, which used to be the standard of care [14]. The WHO now recommends the use of TDF as part of the backbone for PEP regimens [15].

We aimed to evaluate factors associated with loss to follow-up (LTFU) following occupational exposure to HIV in a referral hospital in Cape Town, South Africa, where the HIV prevalence is $12.7 \%$ [16]. We conducted our study in a period when we switched to TDF based PEP, and ensured we had sufficient power to determine variables associated with LTFU.

\section{Methods}

\section{Study setting}

Data was collected from the Occupational Health Clinic (OHC) of Groote Schuur Hospital, a referral hospital in Cape Town, South Africa. HCWs who have significant occupational HIV exposure are started on PEP if they present within $72 \mathrm{~h}$ of the exposure. During the study period the South African national guidelines for PEP recommended the use of TDF and emtricitabine for exposures presenting within $72 \mathrm{~h}$. The policy of adding a 3rd antiretroviral (usually a boosted protease inhibitor) was changed during the study period: initially this was added only for high risk exposures, but subsequently this was added for all exposures. HCWs are counselled about the risks of HIV, the need to document HIV testing for possible compensation, and potential adverse drug reactions to PEP. HIV status of the HCW was determined at baseline using 4th generation Roche COBAS HIV-1/2 Combo automated test with a confirmatory Siemens Integral 4th generation ELISA. PEP was discontinued in HCWs who tested HIV seropositive at baseline. HIV testing was repeated at week 6 (when HCWs were informed that HIV tests may be false negative), and months 3 and 6 after the exposure. Confidentiality of HCWs is protected by keeping all files in the $\mathrm{OHC}$ and not in the general records department; only $\mathrm{OHC}$ clinic staff are able to access the files.

\section{Study design}

We conducted a retrospective cohort review to identify the factors associated with LTFU in HCWs following occupational HIV exposure. The OHC maintains an electronic database of all visits related to $\mathrm{HCW}$ occupational HIV exposures. We collected data from the database and additional data from folders between January 2013 and September 2015, with 29 additional folders obtained in 2012.

\section{Outcomes}

The primary outcome was the proportion of HCWs LTFU at the 3-month visit, which is the key follow-up date to determine if HIV seroconversion has occurred, in keeping with the WHO guidelines [15]. Secondary outcomes were the proportion of HCWs LTFU at the 6-week and 6-month visits.

\section{Data collection}

Data collection at the OHC is collated from an "Occupational Health Clinic Percutaneous Inoculation Report" form. The data are collected each time the HCW presents for follow-up or when contacted by telephone. This form is completed by the occupational health worker on duty, who is either the nurse or doctor. Once 6 months have lapsed since the last visit, the data collected are recorded in an electronic database using Microsoft Excel and $\mathrm{HCW}$ folders are then archived in the clinic.

\section{Study population \\ Inclusion criteria}

HCWs were categorized into three groups: 'Doctors', 'Students' and 'Allied Health Professionals' (e.g. nursing, physiotherapists, occupational therapists, administrative clerks, pharmacists, and emergency medical services). HCWs were included if they were exposed to potentially infectious material from patients who are HIV-infected or HIV status unknown and attended the OHC. The following materials were deemed to be potentially infectious: pleural, pericardial, peritoneal, cerebrospinal, synovial fluid, amniotic fluid, and blood [17].

\section{Exclusion criteria}

Exclusion criteria were: HCW tested HIV seropositive at baseline; exposed to a HIV seronegative source; those who requested follow-up at a private doctor or who went back to their own training institutions, such as elective students; multiple exposures within the 6-month followup period; exposures deemed to be from non-infectious material [17].

\section{Sample size estimation}

We selected seven variables a priori for inclusion into our model based on our review of the literature: age at exposure, sex, HCW category, type of exposure, source patient HIV status, dual or triple antiretroviral therapy (ART), and time from exposure to time of receiving PEP. Assuming 25\% LTFU at 3 months, [12] we required a sample size of 280 to ensure a minimum of 10 outcome events per variable, which are needed to improve precision and minimize bias in logistic regression models [18]. 


\section{Statistical analysis}

All statistical analysis was performed using Stata (Version 13.1; Stata Corp, College Station, Texas, USA). Descriptive statistics were used to characterize the total sample, and results were expressed as median (interquartile range) for non-normally distributed continuous variables, and frequencies and percentages for categorical variables.

We used separate multivariable logistic regression models for each time point to identify factors associated with LTFU at the 3-month, 6-week, and 6-month followup visits. The full model approach was utilized using a priori selected variables in order to ensure decreased risk of selection bias and overfitting [19]. This approach allows multiple epidemiological variables to be assessed independently while controlling effects of other variables [20]. Univariate analysis was used to estimate crude odds ratios (ORs) and 95\% confidence intervals (95\% CIs), while multivariable logistic regression provided adjusted estimates for odds of LTFU at each time point. Odds ratios were presented with $95 \%$ CIs and a level of $P<0.05$ was considered statically significant.

\section{Results}

Two hundred and sixty-four folders were obtained between January 2013 and September 2015, with an additional 29 folders collected according to alphabetical order in 2012. There was incomplete data on $12 \mathrm{HCWs}$ who were included in the descriptive analysis but excluded from the univariate and multivariate analysis as shown in Fig. 1.

The characteristics of the 293 patients from our cohort are shown in Table 1 . The dual nucleotide/nucleoside reverse transcriptase inhibitors used in PEP were TDF (97\%), zidovudine (2\%), and stavudine $(1 \%)$; all of which were combined with either lamivudine or emtricitabine. The third agent used in $210 \mathrm{HCWs}$ who were given triple ART was lopinavir/ritonavir (82\%), atazanavir/ritonavir (13\%), raltegravir (4\%), and efavirenz (1\%).

LTFU at the various visits were: $36 \%$ at 6 weeks, $60 \%$ at 3 months, and $72 \%$ at 6 months (Table 1). The univariate and multivariate analysis of variables associated with LTFU at the 3-month visit are shown in Table 2 . In the multivariate analysis, significant risk factors associated with LTFU were: younger age, HCW category of doctor, and time from exposure to receiving PEP of more than $24 \mathrm{~h}$. The multivariate analysis of variables associated with LTFU at the 6-week and 6-month follow-up visits are shown in Table 3 . Variables associated with LTFU at the 6-week visit were: male sex and HCW category of doctor. Variables associated with LTFU at the 6-month visit were similar to the 3-month visit: younger age, $\mathrm{HCW}$ category of doctor, and time from exposure to receiving PEP of more than $24 \mathrm{~h}$.

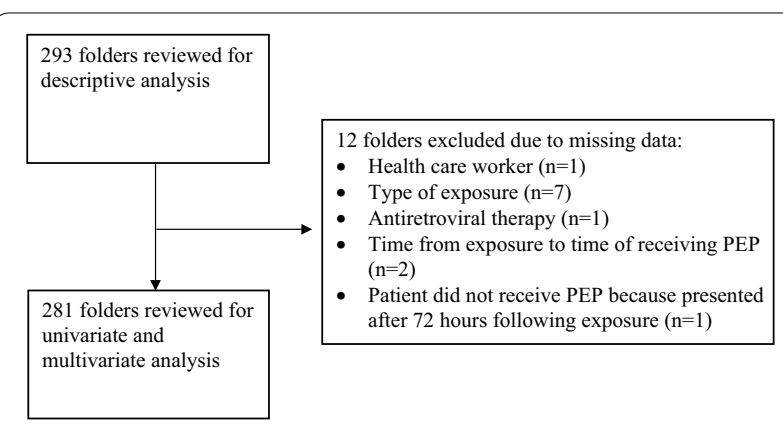

Fig. 1 Flow chart illustrating data set of health care workers chosen for analysis

Table 1 Baseline characteristics and follow-up of 293 health care workers with occupational exposure

\begin{tabular}{|c|c|}
\hline Variable & Sample (n) \\
\hline Age, median (IQR) & $28(24-35)$ \\
\hline \multicolumn{2}{|l|}{ Sex } \\
\hline Women & $197(67 \%)$ \\
\hline Men & $96(33 \%)$ \\
\hline \multicolumn{2}{|l|}{ Health care worker ${ }^{a}$} \\
\hline Allied health professional & $85(29 \%)$ \\
\hline Doctor & $100(34 \%)$ \\
\hline Student & $107(37 \%)$ \\
\hline \multicolumn{2}{|l|}{ Type of exposure ${ }^{b}$} \\
\hline Hollow-bore & $137(48 \%)$ \\
\hline Mucocutaneous & $86(30 \%)$ \\
\hline Solid sharp & $63(22 \%)$ \\
\hline \multicolumn{2}{|l|}{ Source patient HIV status } \\
\hline Positive & $246(84 \%)$ \\
\hline Unknown & $47(16 \%)$ \\
\hline \multicolumn{2}{|l|}{ Antiretroviral ${ }^{c, f}$} \\
\hline Dual & $81(28 \%)$ \\
\hline Triple & $210(72 \%)$ \\
\hline \multicolumn{2}{|c|}{ Time from exposure to receiving PEPd (h) } \\
\hline$<24$ & $268(92 \%)$ \\
\hline $24-48$ & $17(6 \%)$ \\
\hline $48-72$ & $1(0.3 \%)$ \\
\hline$>72$ & $4(1.4 \%)$ \\
\hline \multicolumn{2}{|l|}{ Loss to follow-up ${ }^{e}$} \\
\hline 6 weeks & $100(36 \%)$ \\
\hline 3 months & $169(60 \%)$ \\
\hline 6 months & $203(72 \%)$ \\
\hline
\end{tabular}

Number with missing data: ${ }^{a} n=1,{ }^{b} n=7,{ }^{c} n=1,{ }^{d} n=2,{ }^{e} n=12$

$f$ One health care worker did not receive PEP because presented too late

LTFU by category of HCW at the various visits is shown in Fig. 2, with doctors having the highest proportion LTFU. 
Table 2 Variables associated with loss to follow-up at 3 months

\begin{tabular}{|c|c|c|c|c|}
\hline Variables & Unadjusted OR ( $95 \% \mathrm{Cl})$ & $P$ value & Adjusted OR (95\% Cl) & $P$ value \\
\hline Age (per 10-year increase) & $0.7(0.5-0.9)$ & 0.003 & $0.6(0.5-0.9)$ & 0.011 \\
\hline \multicolumn{5}{|l|}{ Sex } \\
\hline \multicolumn{5}{|l|}{ Women $^{a}$} \\
\hline Men & $1.4(0.8-2.4)$ & 0.190 & $1.4(0.8-2.5)$ & 0.262 \\
\hline \multicolumn{5}{|l|}{ Health care worker } \\
\hline \multicolumn{5}{|l|}{ Allied health professional ${ }^{a}$} \\
\hline Doctor & $2.9(1.6-5.4)$ & 0.001 & $2.7(1.3-5.5)$ & 0.006 \\
\hline Student & $2.0(1.1-3.6)$ & 0.022 & $1.2(0.6-2.6)$ & 0.584 \\
\hline \multicolumn{5}{|l|}{ Type of exposure } \\
\hline \multicolumn{5}{|l|}{ Hollow-bore } \\
\hline Mucocutaneous & $1.6(0.9-2.9)$ & 0.095 & $1.1(0.6-2.2)$ & 0.707 \\
\hline Solid sharp & $1.3(0.7-2.4)$ & 0.377 & $1.0(0.5-1.9)$ & 0.948 \\
\hline \multicolumn{5}{|l|}{ Source patient HIV status } \\
\hline Positive & $0.9(0.4-1.8)$ & 0.742 & $0.5(0.2-1.1)$ & 0.074 \\
\hline \multicolumn{5}{|l|}{ Unknown ${ }^{\mathrm{a}}$} \\
\hline \multicolumn{5}{|l|}{ Antiretroviral } \\
\hline Dual & $1.4(0.8-2.3)$ & 0.250 & $1.5(0.8-2.8)$ & 0.228 \\
\hline \multicolumn{5}{|l|}{ Triple ${ }^{\mathrm{a}}$} \\
\hline \multicolumn{5}{|c|}{ Time from exposure to receiving PEP (h) } \\
\hline \multicolumn{5}{|l|}{$<24^{\mathrm{a}}$} \\
\hline$>24$ & $3.0(1.0-9.2)$ & 0.052 & $5.9(1.3-26.9)$ & 0.023 \\
\hline
\end{tabular}

a Reference category

\section{Discussion}

We showed that LFTU of HCWs after occupational HIV exposure was high and increased with successive visits. Younger age, the $\mathrm{HCW}$ category doctor, and time from exposure to receiving PEP of more than $24 \mathrm{~h}$ were associated with LTFU at the 3-month visit, which was our primary endpoint. Men were more likely to be LTFU at the 6 -week visit than women. These findings could be used to target interventions designed to improve follow-up.

Our finding that LTFU increases with successive visits is consistent with other studies $[9,12,13]$. We found that younger age was a significant risk factor for LTFU, which is in keeping with other studies [21-23]. The higher LTFU in younger HCWs may be related to the greater change and instability they experience in their younger years [24]. Men tended to be more likely to be LTFU in our study, which is similar to the findings of Escurdero et al. [13].

The majority (207 out of 281) of HCWs in our study were doctors and students. Doctors and students are often involved in invasive medical procedures, which places them at risk of being exposed to infectious material $[7,9,11,25]$. Furthermore, students and doctors with less than a year's experience, are prone to occupational exposure because of their inexperience $[7,9,26]$. We found that doctors are more likely to be LTFU than other $\mathrm{HCW}$ categories. This could be explained by the ease with which doctors can submit their own blood samples for HIV testing instead of attending the OHC. One study, [27] showed a large proportion of HCWs obtained HIV testing outside of the facility where they worked, which they suggested was due to concern surrounding the confidentiality of HIV testing at the facility. Furthermore, doctors may be making their own assessment of the severity of the exposure and may deem it unnecessary to followup [28]. In contrast to our findings of increased LTFU in doctors, Gutierrez et al. [6] showed cleaning personnel were more likely to be LTFU. Two other studies found type of HCW category did not influence attendance to follow-up [12, 13].

Longer time from exposure to receiving PEP at the 3 -month visit was positively associated with LTFU. This could be explained by HCWs who present after $24 \mathrm{~h}$ having a perceived lower benefit from PEP. However, type of exposure and source patient HIV status, which are associated with risk of HIV acquisition, were not associated with LTFU in our cohort.

Escudero et al. [13] also found that type of exposure was not related to attendance to follow-up. Findings from studies that assessed the effect of the source patient's HIV status on LTFU are contradictory, with one study reporting no effect, [6] while another found positive serological status was associated with improved follow up [13]. 
Table 3 Variables associated with loss to follow-up at 6 weeks and 6 months

\begin{tabular}{|c|c|c|c|c|}
\hline \multirow[t]{2}{*}{ Variables } & \multicolumn{2}{|l|}{ 6-week } & \multicolumn{2}{|l|}{ 6-month } \\
\hline & $\begin{array}{l}\text { Adjusted } \\
\text { OR }\end{array}$ & $\begin{array}{l}P \\
\text { value }\end{array}$ & $\begin{array}{l}\text { Adjusted } \\
\text { OR }\end{array}$ & $\begin{array}{l}P \\
\text { value }\end{array}$ \\
\hline Age (per 10-year increase) & $1.0(0.7-1.3)$ & 0.764 & $0.6(0.5-0.9)$ & 0.010 \\
\hline \multicolumn{5}{|l|}{ Sex } \\
\hline \multicolumn{5}{|l|}{ Women $^{\mathrm{a}}$} \\
\hline Men & $1.8(1.1-3.2)$ & 0.027 & $1.8(0.9-3.4)$ & 0.082 \\
\hline \multicolumn{5}{|l|}{ Health care worker } \\
\hline \multicolumn{5}{|l|}{$\begin{array}{l}\text { Allied health } \\
\text { professional }^{\mathrm{a}}\end{array}$} \\
\hline Doctor & $2.1(1.1-4.4)$ & 0.034 & $2.1(1.0-4.5)$ & 0.049 \\
\hline Student & $1.1(0.5-2.5)$ & 0.750 & $1.3(0.6-2.9)$ & 0.532 \\
\hline \multicolumn{5}{|l|}{ Type of exposure } \\
\hline \multicolumn{5}{|l|}{ Hollow-bore ${ }^{a}$} \\
\hline Mucocutaneous & $1.0(0.5-1.9)$ & 0.988 & $1.2(0.6-2.5)$ & 0.659 \\
\hline Solid sharp & $1.1(0.5-2.1)$ & 0.857 & $1.1(0.5-2.4)$ & 0.728 \\
\hline \multicolumn{5}{|l|}{ Source patient HIV status } \\
\hline Positive & $1.0(0.5-2.2)$ & 0.952 & $0.7(0.3-1.7)$ & 0.489 \\
\hline \multicolumn{5}{|l|}{ Unknown ${ }^{\mathrm{a}}$} \\
\hline \multicolumn{5}{|l|}{ Antiretroviral } \\
\hline Dual & $1.2(0.6-2.3)$ & 0.544 & $0.7(0.4-1.4)$ & 0.333 \\
\hline \multicolumn{5}{|l|}{ Triple ${ }^{\mathrm{a}}$} \\
\hline \multicolumn{5}{|c|}{ Time from exposure to receiving PEP (h) } \\
\hline \multicolumn{5}{|c|}{$<24^{\mathrm{a}}$} \\
\hline$>24$ & $1.3(0.5-3.4)$ & 0.552 & $7.8(1.0-61)$ & 0.049 \\
\hline
\end{tabular}

There are a number of studies which reported that dual ART regimens are better tolerated than triple regimens $[29,30]$. However, many of these studies include ART that are no longer used due to toxicity. Newer studies have shown that completion of PEP is based on the tolerability of ART and not on whether dual or triple therapy are used [31,32]. This could explain why in our cohort there was no correlation between type of ART used and LTFU.

There were several limitations of our study. First, the retrospective cohort design is inherently prone to bias. However, the data was captured by OHC staff on a standard form and we had very little missing data. Second, although we found that time from exposure to receiving PEP was associated with LTFU, the $95 \%$ CIs were wide due to the small sample size of HCWs with delayed presentation. Third, we did not explore associations between years of HCW experience and exposure as we did not have this data. Other researchers have reported an association between years of experience and the incidence of occupational exposures [7, 9, 25]. Finally, Groote Schuur Hospital is a tertiary facility with referrals from other hospitals that fall under the University of Cape Town, so our findings may not be generalizable to other settings such as district hospitals.

We have identified factors associated with LTFU, which could be used to target interventions to decrease LTFU. In one study, [13] contacting HCWs by telephone or mail improved attendance to follow-up from 33 to $54 \%$. Schmid et al. [33] suggested attendance to follow-up could be improved with fewer follow-up visits. The WHO has recently advised the final follow-up visit should be at 3 months rather than 6 months [15]. Furthermore, it has been suggested that the last follow-up visit should be at 6 weeks if laboratory 4th generation HIV ELISA tests are utilized, and 8 weeks if 4 th generation rapid HIV tests are utilized [34]. Lastly van der Maaten et al. [9] suggested increasing awareness of the availability of PEP through campaigns.

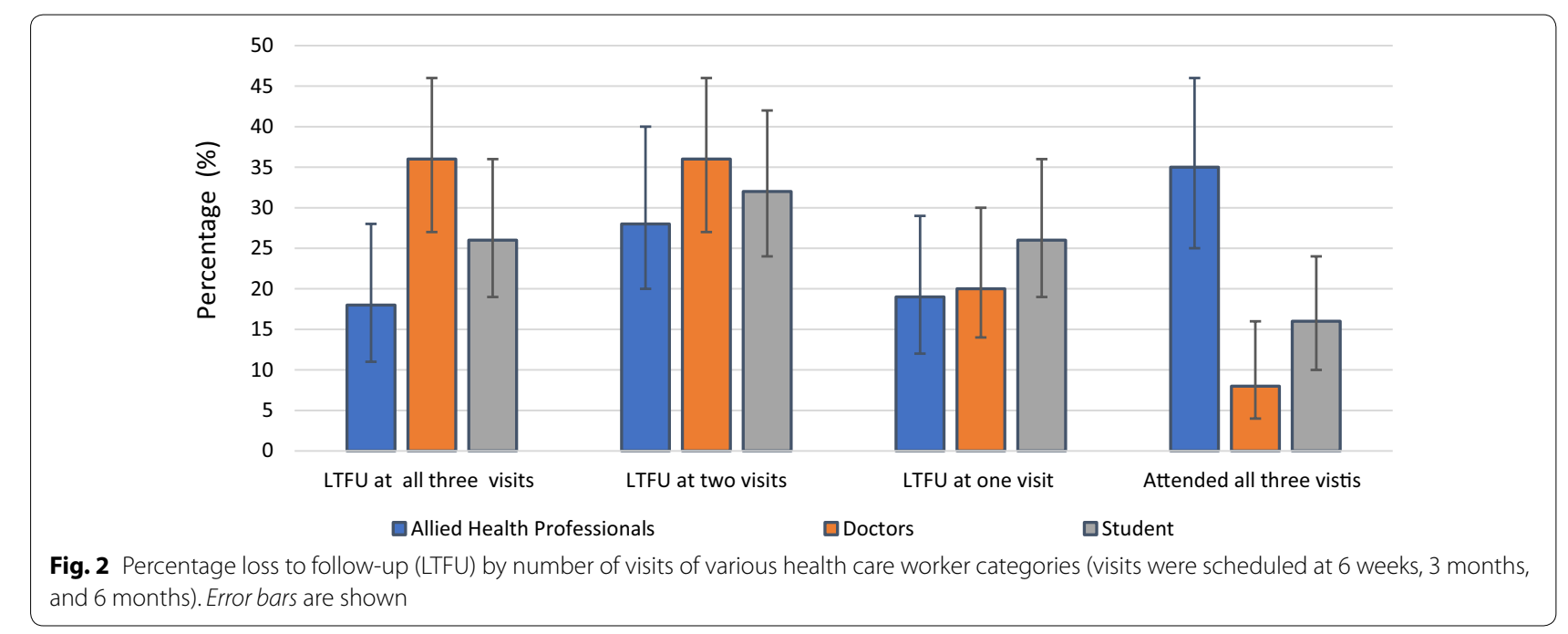




\section{Conclusion}

We have identified factors associated with LTFU of HCWs after occupational HIV exposure. Future research should identify measures to improve attendance to follow-up, which could be targeted at doctors, younger $\mathrm{HCWs}$, and HCWs with delayed presentation.

\section{Abbreviations}

ART: antiretroviral therapy; Cls: confidence intervals; HCW: health care worker; HIV: human immunodeficiency virus; LTFU: Ioss to follow-up; OHC: Occupational Health Clinic; ORs: odds ratios; PEP: post exposure prophylaxis; TDF: tenofovir disoproxil fumarate; WHO: World Health Organization.

\section{Authors' contributions}

NP and GM designed the study, wrote the proposal, analyzed the data, and prepared the manuscript. KM was involved in proposal writing, statistical analysis, and manuscript preparation. NP, FC and MG were involved in data collection. All authors read and approved the final manuscript.

\section{Author details}

${ }^{1}$ Department of Medicine, Old Main Building, J-Floor, Groote Schuur Hospital, University of Cape Town, Observatory, Cape Town 7925, South Africa. ${ }^{2}$ Trauma and Emergency Unit, Floor E11A, Management Suite, Groote Schuur Hospital, Main Road, Observatory, Cape Town 7925, South Africa. ${ }^{3}$ Quality and Safety Unit, Groote Schuur Hospital, Main Road, Observatory, Cape Town 7925, South Africa. ${ }^{4}$ Division of Clinical Pharmacology, Department of Medicine, Groote Schuur Hospital, University of Cape Town, Cape Town 7925, South Africa.

\section{Acknowledgements}

Not applicable.

\section{Competing interests}

The authors declare they have no competing interests.

\section{Availability of data and materials}

Data sets are available from the corresponding author on reasonable request.

\section{Ethics approval}

Ethical approval was obtained from the Human Research Ethics Committee of the University of Cape Town.

\section{Funding}

GM received partial support from the National Research Foundation of South Africa (Grant Reference Number 85810).

\section{Publisher's Note}

Springer Nature remains neutral with regard to jurisdictional claims in published maps and institutional affiliations.

Received: 21 March 2017 Accepted: 13 April 2017

Published online: 21 April 2017

\section{References}

1. World Health Organization. The world health report 2002, chapter 4 reducing risks, promoting healthy life. http://www.who.int/whr/2002/ chapter4/en/index8.html. Accessed 21 Mar 2016.

2. Cohen MS, Chen YQ, McCauley M, Gamble T, Hosseinipour MC, Kumarasamy $\mathrm{N}$, et al. Prevention of HIV-1 infection with early antiretroviral therapy. N Engl J Med. 2011;365(6):493-505.

3. Lundgren JD, Babiker AG, Gordin F, Emery S, Grund B, Sharma S, et al. Initiation of antiretroviral therapy in early asymptomatic HIV infection. N Engl J Med. 2015;373(9):795-807.
4. de la Tribonniere X, Dufresne MD, Alfandari S, Fontier C, Sobazek A, Valette $M$, et al. Tolerance, compliance and psychological consequences of post-exposure prophylaxis in health-care workers. Int J STD AIDS. 1998;9(10):591-4.

5. Pungpapong S, Phanuphak P, Pungpapong K, Ruxrungtham K. The risk of occupational HIV exposure among Thai healthcare workers. Southeast Asian J Trop Med Public Health. 1999:30(3):496-503.

6. Gutierrez EB, Heloísa Lopes M, Shikanai Yasuda MA. Accidental exposure to biological material in healthcare workers at a university hospital: evaluation and follow-up of 404 cases. Scand J Infect Dis. 2005:37(4):295-300.

7. Jayanth ST, Kirupakaran H, Brahmadathan KN, Gnanaraj L, Kang G. Needle stick injuries in a tertiary care hospital. Indian J Med Microbiol. 2009;27(1):44-7.

8. Siika AM, Nyandiko WM, Mwangi A, Waxman M, Sidle JE, Kimaiyo SN, et al The structure and outcomes of a HIV postexposure prophylaxis program in a high HIV prevalence setup in western Kenya. J Acquir Immune Defic Syndr. 2009:51(1):47-53.

9. van der Maaten GC, Nyirenda M, Beadsworth MJ, Chitani A, Allain T, van Oosterhout JJ. Post exposure prophylaxis of HIV transmission after occupational injuries in Queen Elizabeth Central Hospital, Blantyre, Malawi, 2003-2008. Malawi Med J. 2010:22(1):15-9.

10. Olowookere SA, Fatiregun AA. Human immunodeficiency virus postexposure prophylaxis at Ibadan, Nigeria. J Int Assoc Phys AIDS Care (Chic). 2010;9(3):187-90.

11. Onyedum CC, Chukwuka C, lyoke CA, Omotola OF. HIV postexposure prophylaxis (PEP) in a Nigerian tertiary health institution. J Int Assoc Phys AIDS Care (Chic). 2011;10(3):171-5.

12. Tetteh RA, Nartey ET, Lartey M, Mantel-Teeuwisse AK, Leufkens HG, Nortey PA, et al. Outcomes of a postexposure prophylaxis program at the KorleBu Teaching Hospital in Ghana: a retrospective cohort study. J Int Assoc Provid AIDS Care. 2015;14(6):544-52.

13. Escudero DV, Furtado GH, Medeiros EA. Healthcare worker adherence to follow-up after occupational exposure to blood and body fluids at a teaching hospital in Brazil. Ann Occup Hyg. 2015;59(5):566-71.

14. Ford N, Shubber Z, Calmy A, Irvine C, Rapparini C, Ajose O, et al. Choice of antiretroviral drugs for postexposure prophylaxis for adults and adolescents: a systematic review. Clin Infect Dis. 2015;60(Suppl 3):S170-6.

15. World Health Organization. Guidelines on post-exposure prophylaxis for HIV and the use of co-trimoxazole prophylaxis for HIV-related infections among adults, adolescents and children: recommendations for a public health approach: December 2014 supplement to the 2013 consolidated guidelines on the use of antiretroviral drugs for treating and preventing HIV infection. http://www.who.int/hiv/pub/guidelines/arv2013/arvs2013upplement_dec2014/en. Accessed 17 Sep 2016.

16. Statistics South Africa. Statistical release, mid-year population estimates 2016. http://www.statssa.gov.za/?page_id=1854\&PPN=P0302. Accessed 22 Jan 2017.

17. Centers for Disease Control. Update: universal precautions for prevention of transmission of human immunodeficiency virus, hepatitis B virus, and other bloodborne pathogens in health-care settings. MMWR Morb Mortal Wkly Rep. 1988;37(24):377.

18. Peduzzi P, Concato J, Kemper $E_{1}$ Holford TR, Feinstein AR. A simulation study of the number of events per variable in logistic regression analysis. J Clin Epidemiol. 1996;49(12):1373-9.

19. Moons KG, Kengne AP, Woodward M, Royston P, Vergouwe Y, Altman DG, et al. Risk prediction models: I. Development, internal validation, and assessing the incremental value of a new (bio)marker. Heart. 2012;98(9):683-90.

20. Stoltzfus JC. Logistic regression: a brief primer. Acad Emerg Med. 2011;18(10):1099-104.

21. Corfield L, Schizas A, Noorani A, Williams A. Non-attendance at the colorectal clinic: a prospective audit. Ann R Coll Surg Engl. 2008;90(5):377-80.

22. Milne V, Kearns R, Harrison A. Patient age, ethnicity and waiting times determine the likelihood of non-attendance at a first specialist rheumatology assessment. Int J Rheum Dis. 2014;17(1):19-25.

23. Hynes L, Byrne M, Dinneen SF, McGuire BE, O'Donnell M, Mc Sharry J. Barriers and facilitators associated with attendance at hospital diabetes clinics among young adults (15-30 years) with type 1 diabetes mellitus: a systematic review. Pediatr Diabetes. 2016;17(7):509-18. 
24. Arnett JJ. Emerging adulthood. A theory of development from the late teens through the twenties. Am Psychol. 2000;55(5):469-80.

25. Karstaedt AS, Pantanowitz L. Occupational exposure of interns to blood in an area of high HIV seroprevalence. S Afr Med J. 2001;91(1):57-61.

26. Aggarwal V, Seth A, Chandra J, Gupta R, Kumar P, Dutta AK. Occupational exposure to human immunodeficiency virus in health care providers: a retrospective analysis. Indian J Commun Med. 2012;37(1):45-9.

27. Kassa G, Selenic D, Lahuerta M, Gaolathe T, Liu Y, Letang G, et al. Occupational exposure to bloodborne pathogens among health care workers in Botswana: reporting and utilization of postexposure prophylaxis. Am J Infect Control. 2016;44(8):879-85.

28. Elmiyeh B, Whitaker IS, James MJ, Chahal CA, Galea A, Alshafi K. Needlestick injuries in the National Health Service: a culture of silence. J R Soc Med. 2004;97(7):326-7.

29. Puro V. Post-exposure prophylaxis for HIV infection. Ital Regist Post Expo Prophyl. Lancet. 2000;355(9214):1556-7.
30. Bassett IV, Freedberg KA, Walensky RP. Two drugs or three? Balancing efficacy, toxicity, and resistance in postexposure prophylaxis for occupational exposure to HIV. Clin Infect Dis. 2004;39(3):395-401.

31. Henderson DK. Management of needlestick injuries: a house officer who has a needlestick. JAMA. 2012;307(1):75-84.

32. McAllister J, Read P, McNulty A, Tong WW, Ingersoll A, Carr A. Raltegraviremtricitabine-tenofovir as HIV nonoccupational post-exposure prophylaxis in men who have sex with men: safety, tolerability and adherence. HIV Med. 2014;15(1):13-22.

33. Schmid K, Schwager C, Drexler H. Needlestick injuries and other occupational exposures to body fluids amongst employees and medical students of a German university: incidence and follow-up. J Hosp Infect. 2007;65(2):124-30

34. Gaines H, Albert J, Axelsson M, Berglund T, Gisslen M, Sonnerborg A, et al. Six-week follow-up after HIV-1 exposure: a position statement from the Public Health Agency of Sweden and the Swedish Reference Group for Antiviral Therapy. Infect Dis (Lond). 2016;48(2):93-8.

\section{Submit your next manuscript to BioMed Central and we will help you at every step:}

- We accept pre-submission inquiries

- Our selector tool helps you to find the most relevant journal

- We provide round the clock customer support

- Convenient online submission

- Thorough peer review

- Inclusion in PubMed and all major indexing services

- Maximum visibility for your research

Submit your manuscript at www.biomedcentral.com/submit 